\title{
Decreased DNA methylation at promoters and gene-specific neuronal hypermethylation in the prefrontal cortex of patients with bipolar disorder
}

Miki Bundo ${ }^{1 \dagger}$, Junko Ueda ${ }^{1,2 \dagger}$, Yutaka Nakachi ${ }^{1}$, Kiyoto Kasai ${ }^{3,4}$, Tadafumi Kato ${ }^{2,5 \#}$, Kazuya Iwamoto ${ }^{1 \#}$

${ }^{1}$ Department of Molecular Brain Science, Graduate School of Medical Sciences, Kumamoto University, Japan

${ }^{2}$ Laboratory for Molecular Dynamics of Mental Disorders, RIKEN Center for Brain Science, Japan

${ }^{3}$ Department of Neuropsychiatry, Graduate School of Medicine, The University of Tokyo, Japan

${ }^{4}$ The International Research Center for Neurointelligence (WPI-IRCN) at The University of Tokyo Institutes for Advanced Study (UTIAS),

${ }^{5}$ Department of Psychiatry and Behavioral Science, Graduate School of Medicine, Juntendo University

$\dagger$ contributed equally to this work

\#corresponding authors:

Kazuya Iwamoto

Department of Molecular Brain Science, Graduate School of Medical Sciences, Kumamoto University. 1-1-1 Honjo, Chuo-ku, Kumamoto, 860-8556, Japan iwamotok@kumamoto-u.ac.jp

Tadadumi Kato

Department of Psychiatry and Behavioral Science, Graduate School of Medicine, Juntendo University. 2-1-1 Hongo, Bunkyo, Tokyo 113-8421, Japan tadafumi.kato@juntendo.ac.jp.

Running title: DNA methylation analysis in bipolar disorder 


\begin{abstract}
Bipolar disorder (BD) is a severe mental disorder characterized by repeated mood swings. Although genetic factors are collectively associated with the etiology of BD, the underlying molecular mechanisms, particularly how environmental factors affect the brain, remain largely unknown. We performed promoter-wide DNA methylation analysis of neuronal and nonneuronal nuclei in the prefrontal cortex of patients with BD $(\mathrm{N}=34)$ and controls $(\mathrm{N}=35)$. We found decreased DNA methylation at promoters in both cell types in the $\mathrm{BD}$ patients compared to the controls. Gene Ontology (GO) analysis of differentially methylated region (DMR)-associated genes revealed enrichment of molecular motor-related genes in neurons, chemokines in both cell types, and ion channel- and transporter-related genes in nonneurons. Detailed analysis further revealed that growth cone- and dendrite-related genes, including NTRK2 and GRIN1, were hypermethylated in neurons of BD patients. To assess the effect of medication, neuroblastoma cells were cultured under therapeutic concentrations of three different mood stabilizers (lithium, valproate, and carbamazepine). We observed that up to $37.9 \%$ of DMRs detected in BD overlapped with mood stabilizer-induced DMRs. Interestingly, mood stabilizer-induced DMRs showed the opposite direction of changes in DMRs in $\mathrm{BD}$, suggesting the therapeutic effects of mood stabilizers on DNA methylation. Among the DMRs, 12 overlapped with loci identified by a previous genome-wide association study of BD. Finally, we performed qPCR analysis of 10 DNA methylation-related genes and found that DNMT3B was overexpressed in BD. The cell type-specific DMRs identified in this study will be useful for understanding the pathophysiology of BD.
\end{abstract}




\section{Introduction}

Bipolar disorder (BD), also known as manic depressive illness, is a severe and common mental disorder characterized by repeated mood swings of depressive and manic episodes, with elevated rates of mortaility ${ }^{1,2}$. Early epidemiological and linkage studies suggested that $\mathrm{BD}$ is a highly heritable disorder caused by a complex interaction of genetic and environmental risk factors ${ }^{3}$. Genome-wide association studies (GWAS) revealed that $\mathrm{BD}$ is a polygenic disorder caused by multiple genetic risks with small effect sizes, similar to schizophrenia (SZ), and shared genetic risks with other psychiatric disorders, such as SZ and autism ${ }^{4-6}$. Additionally, the contribution of de novo loss-of-function mutations, as well as de novo copy number variations, has been suggested in the etiology of $\mathrm{BD}^{7-9}$. Although the genetic landscape of $\mathrm{BD}$ is gradually becoming understood, heritability estimated from epidemiological studies is modestly accounted for by these genetic studies.

Epigenetics, including DNA methylation, reflects gene-environment interactions during development and affects long-lasting gene expression status in cells $^{10}$. Therefore, unraveling the epigenetic landscape of psychiatric disorders will contribute to the understanding of the heritability and pathophysiology of psychiatric disorders $^{11-13}$. In BD, several candidate-gene-based approaches have been performed, such as BDNF, COMT, and SLC6A4 genes in postmortem brains ${ }^{12}$. Additionally, comprehensive DNA methylation studies have revealed expression-linked DNA methylation changes in the cerebellum ${ }^{14}$, accelerated aging in the hippocampus ${ }^{15}$, loss of brain laterality associated with $T G F B 2$ methylation $^{16}$, and methylation imbalance of synaptic function-related genes between the frontal and temporal cortices ${ }^{17}$. However, there have been no established findings that were replicated in multiple studies. 
DNA methylation status in brain cells shows great variation among cell types $^{18-20}$. Therefore, cell type-specific epigenetic analysis will also be important. Recent studies have highlighted that cell type-specific epigenetic differences are linked to $\mathrm{SZ}$ and neuropsychiatric traits ${ }^{21-24}$. In $\mathrm{BD}$, hypomethylation of the $I G F 2$ enhancer, which is associated with increased tyrosine hydroxylase protein levels, has been reported in isolated neuronal nuclei ${ }^{25}$.

In this study, we performed promoter-wide DNA methylation analysis of neuronal and nonneuronal nuclei in the prefrontal cortex (PFC) of patients with BD. In addition to identifying cell type-specific differentially methylated regions (DMRs), we found hypomethylation at promoters in both cell types in BD patients. The affected genes included hypomethylation of molecular motor-related genes in neurons, chemokine-related genes in both cell types, and ion channel- and transporter-related genes in nonneurons. We also found neuron-specific hypermethylation of growth coneand dendrite-related genes. We then assessed the effect of medication by using neuroblastoma cells and found that up to $37.9 \%$ of DMRs in BD patients overlapped with mood stabilizer-induced DMRs. Interestingly, mood stabilizer-induced DMRs showed the opposite direction of changes in DMRs in BD, suggesting the therapeutic effects of mood stabilizers on DNA methylation. Among the DMRs, 12 overlapped with loci identified by a previous GWAS of $\mathrm{BD}^{6}$. We also found overexpression of DNMT3B in BD and SZ, suggesting possible molecular mechanisms of neuronal hypermethylation.

\section{Materials and Methods}

\section{Postmortem brains}


PFC (Brodmann area 46) samples of patients with BD $(\mathrm{N}=34)$ and controls $(\mathrm{N}=35)$ were obtained from the Stanley Medical Research Institute. Among them, selected samples were also analyzed by reduced representation bisulfite sequencing (RRBS). Demographic variables are summarized in Table S1. This study was approved by the ethics committees of participating institutes (the Research Ethics Committee of Kumamoto University, the Research Ethics Committee of the Faculty of Medicine of The University of Tokyo, the Ethical Review Board of Juntendo University, and the Wako 1st Research Ethics Committee of RIKEN).

\section{Nuclei preparation}

Neuronal and nonneuronal nuclei fractions were separated by NeuN-based cell sorting ${ }^{18}$. In brief, after homogenization of fresh-frozen brain samples, the nuclear fraction was retrieved by Percoll discontinuous density gradient centrifugation. An anti-NeuN antibody (\#MAB377, Millipore, Burlington, MA, USA) conjugated with Alexa Fluor 488 was used for staining. NeuN+ and NeuN- nuclei were sorted using the FACS Aria system (BD Biosciences, Franklin Lakes, NJ, USA) as previously described ${ }^{18}$.

\section{Cell culture}

Cell culture and drug conditions were as previously described ${ }^{26}$. In brief, cells of the human neuroblastoma cell line SK-N-SH (American Type Culture Collection) were cultured for 8 days in Eagle's minimal essential medium containing $10 \%$ fetal bovine serum with one of three mood stabilizers. The medium was changed on days 2,5 , and 8 . On day 9, the cells were retrieved. We used three mood stabilizers: lithium chloride (Sigma-Aldrich; St. Louis, MO, USA), valproic acid sodium salt (Sigma-Aldrich), and 
carbamazepine (Sigma-Aldrich). Valproate and lithium were directly dissolved into the medium. Carbamazepine was dissolved in dimethyl sulfoxide before it was added to the medium. The concentration of each drug was determined based on the therapeutic concentrations for BD patients. We prepared the following minimum and maximum therapeutic concentrations: valproate, $0.3 \mathrm{mM}$ and $0.6 \mathrm{mM}$; lithium, $0.6 \mathrm{mM}$ and 1.2 $\mathrm{mM}$; and carbamazepine, $0.05 \mathrm{mM}$ and $0.1 \mathrm{mM}$.

\section{Enrichment of methylated DNA and tiling arrays}

Enrichment of methylated DNA was performed using MethylCollector (Active Motif, Carlsbad, CA, USA) according to the manufacturer's protocol. A total of $100 \mathrm{ng}$ of DNA was used, and methylated DNA was retrieved in $100 \mu \mathrm{L}$ of elution buffer. In qPCR, aliquots of eluted methylated DNA were used for quantification. Probe preparation and labeling for Affymetrix human promoter $1.0 \mathrm{R}$ tiling arrays were performed according to the Affymetrix chromatin immunoprecipitation assay protocol (Affymetrix, Santa Clara, CA, USA) as previously described in detail ${ }^{18}$. The array covers 25,500 human promoters by 4.6 million 25-mer oligo probes. Each promoter covers approximately $7.5 \mathrm{~kb}$ upstream through $2.5 \mathrm{~kb}$ downstream of the transcription start site by 35 bp probe spacing.

\section{Data analysis}

In the postmortem brain experiment, all experiments were performed in duplicate using independently prepared probes (experiments 1 and 2). The total numbers of array data points were therefore 136 and 140 for BD patients and controls, respectively, which have been deposited in the Gene Expression Omnibus as GSE137921. References were 
prepared by applying human genomic DNA amplified by a GenomiPhi V2 DNA amplification kit (GE Healthcare, Chicago, IL) to MethylCollector. The number of methylated regions (MRs) of each sample was counted by MAT software ${ }^{27}$ using two replicate sample datasets (experiments 1 and 2) as one target group and a reference dataset (whole-genome amplified samples) as a reference group. The number of MRs was compared using the Mann-Whitney test. Principal component analysis (PCA) of MRs based on Jaccard statistics was conducted using bedtools ${ }^{28}$. DMRs were independently identified in experiments 1 and 2 by comparing the patient and control datasets. The DMRs detected in experiments 1 and 2 were then intersected by bedtools and used for further analysis.

The parameters used in the MAT were as follows: bandwidth, 300 bp; max gap, 300; min probe, 10; P-value, 1e-3. The MRs and DMRs on the sex chromosomes were excluded from this analysis. DMRs within multigene families, such as olfactory receptors and protocadherins, were removed from the analysis. Annotation was conducted using HOMER ${ }^{29}$. DMR-associated genes were additionally identified if the distance between the intergenic DMR and the nearest TSS was less than $5 \mathrm{~kb}$. Gene Ontology (GO) analysis was performed with ToppGene ${ }^{30}$. The chromosomal location of the DMRs was visualized using CHARANGO software ${ }^{31}$.

\section{RRBS}

RRBS was performed using the MethylSeq library construction, sequencing, and data analysis service (Zymo Research, Irvine, CA, USA). The total number of RRBS data points was 10 each for the BD and controls, which has been deposited in the DDBJ Sequence Read Archive as DRA008934. In brief, a total of 500 ng of genomic DNA 
was digested with Taq I and Msp I. DNA fragments were filled in, and A was added at the 3 '-end, followed by adaptor ligation. After bisulfite modification using the EZ DNA methylation-Direct kit (Zymo Research), preparative-scale PCR was performed. Size selection was performed on a 4\% NuSieve 3:1 agarose gel. Library material was recovered using a Zymoclean Gel DNA recovery kit (Zymo Research). DNA sequencing was performed using an Illumina HiSeq2000. The data were analyzed using a Zymo Research proprietary pipeline (Zymo Research). We used CpG sites 1) with coverage $\geq 10$ and 2) located within DMRs detected in the array analysis, which corresponded to 4,959 and 3,281 CpG sites for neuronal and nonneuronal DMRs, respectively. Statistical analyses were conducted by a one-tailed Student's t-test.

\section{Quantitative RT-PCR}

Real-time quantitative RT-PCR was performed according to a previous study ${ }^{32}$. A total of $1 \mu \mathrm{g}$ of total RNA was used for cDNA synthesis by oligo (dT) and SuperScript II reverse transcriptase (Invitrogen). qRT-PCR was performed using SYBR/GREEN I dye (Applied Biosystems, Foster City, CA, USA) with ABI PRISM 7900HT (Applied Biosystems). The comparative $\mathrm{Ct}$ method (Applied Biosystems) was employed for quantification. We used two internal control genes based on our previous analysis ${ }^{32}$. In addition to analyzing all the measured samples, we performed $\mathrm{pH}$-adjusted analysis because the brain sample $\mathrm{pH}$ systematically affects the transcriptome ${ }^{33}$. Low $\mathrm{pH}$ samples $(\mathrm{pH}<6.4)$ were omitted from the $\mathrm{pH}$-adjusted analysis. The threshold was previously determined ${ }^{34} . \mathrm{P}<0.05$ in the Mann-Whitney test was considered significant. Primer pairs used in this study were as follows: MBD1, 5'AGGAGGACAAGGAGGAGAACAA-3' and 
5'-GGCTGAAAATCTCCGTGATCAC-3';

MBD2,

5'-TCCAGGCAGAACCAATCCTTTC-3'

and

5'-AAAAGACATGGTCCCTGCCCT-3';

MBD2L,

5'-GTTTGGCTTAACACATCTCAACCC-3'

and

5'-GTACTCGCTCTTCCTGTTTCCTGA-3';

MBD3,

5'-GCTCCCTGTCAGAGTCAAAGCAC-3'

and

5'-GCACCAACCTCAGGAAGACGT-3';

MBD4,

5'-AATGGACACCTCCTCGGTCACC-3'

and

5'-CTTCCAAAGCACAGGTATTGCC-3';

DNMT1,

5'-CACTGCACGTGTTTGCTCC-3' and 5'-ACCCGAGCTCAACCTGG-3'; DNMT2,

5'-TATGCGGTGACATGGATGAAC-3' and 5'-TCTCATCACCCCAATCAGAAAC-3';

DNMT3A, 5'-AACCTTCCCGGTATGAACAGGC-3' and

5'-TGCTGAACTTGGCTATCCTGCC-3';

DNMT3B,

5'-CCGTGACTGCAATAGAACCCTC-3'

and

5'-AGAACTCAGCACACCCCTTCCT-3';

MECP2,

5'-GCCTCCTTTCCGTTTGATTTG-3' and

5'-CACATTGAGTAACAGTCCTGGTGA-3'. For each primer pair, amplification of the single product was confirmed by gel electrophoresis and by monitoring the dissociation curve.

\section{Data availability}

The array data are available under accession GSE137921. The RRBS data are available under accession DRA008934. 


\section{Results}

\section{Widespread promoter hypomethylation of the PFC in patients with BD}

We performed promoter-wide DNA methylation analysis on NeuN-sorted neuronal $(\mathrm{NeuN}+)$ and nonneuronal (NeuN-) nuclear fractions derived from the PFC of patients with BD $(\mathrm{N}=34)$ and controls $(\mathrm{N}=35)$ (Table S1). DNA fragments containing densely methylated CpGs were enriched using the MBD2B/3L complex and analyzed with a promoter tiling array. PCA of the DNA methylation signature revealed a clear separation between neurons and nonneurons (Fig. 1a). We then compared the total number of MRs per sample (Fig. 1b). Consistent with our previous report ${ }^{18}$, the total number of MRs was significantly lower in neurons than in nonneurons within controls $(\mathrm{P}=0.0006)$ and within patients $(\mathrm{P}=4.75 \mathrm{E}-05)$. Additionally, a significant decrease in the total number of MRs was identified in both neurons and nonneurons of patients compared to controls ( $\mathrm{P}=0.0031$ and $\mathrm{P}=0.0318$, respectively, in the Mann-Whitney test). The decreased number of MRs in the patients was not dependent on the genomic context, such as repeat structure or segmental duplications (Fig. S1), implying genomic context-independent, promoter-wide hypomethylation in the cells of the PFC of patients with BD.

\section{Identification and characterization of DMRs}

We then identified DMRs between BD patients and controls in each cell type (Tables S2 and S3). The DMRs of neurons and nonneurons are uniformly distributed throughout the genome (Fig. 1c). Consistent with the decreased number of MRs in BD, most DMRs in both neurons and nonneurons showed hypomethylation (Fig. 1d). The overlaps between neurons and nonneurons at the gene level ranged from $23.4 \%$ to $44.1 \%$. The 
rest showed cell-type-specific DNA methylation changes (Fig. 1e). We performed GO analysis using all the DMR-associated genes (Fig 2a). Each of the significantly enriched GO terms was composed of neuronal and nonneuronal DMR-associated genes at different ratios (Fig. 2a). We found that kinesin complex-, microtubule-, and motor molecule-related genes dominantly included neuronal DMR-associated genes, whereas chemokine activity-related and inflammation-related genes were evenly enriched among both neuronal and nonneuronal DMR-associated genes. In contrast, ion channels and transporter-related terms mainly included nonneuronal DMR-associated genes. To further extract the cell-type-specific signature, we performed stratified GO analysis considering cell type and direction of methylation change (Fig. 2b, Table S5). Strikingly, hypermethylated genes in neurons included genes related to the growth cone and dendrites (Fig. 2b), such as the NMDA NR1 subunit gene GRINI and the BDNF receptor gene NTRK2 (Fig. 2c). Both genes have been the long-studied genes in psychiatric disorders, and their downregulation in the postmortem brains of BD patients has been established (see Discussion). On the other hand, kinesin complex- and microtubule motor activity-related genes were included in the hypomethylated genes of neurons (Fig. 2b, Table S5).

\section{Technical considerations of MRs and DMRs by RRBS and qPCR}

We performed RRBS analysis in neurons and nonneurons of the selected subjects (Tables S1 and S6). Approximately 95\% of the MRs detected in the array showed greater than $70 \%$ of the DNA methylation levels in RRBS, ensuring high sensitivity to the detection of methylated DNA (Fig. S2). A total of 999 DMRs contained at least one CpG site whose DNA methylation level could be determined by RRBS. Among them, 
190 DMRs contained CpG(s) showing significant DNA methylation differences by RRBS (Fig. S2). The average validation rates by RRBS were $16.4 \%$ for hypomethylation and $52.7 \%$ for hypermethylation. Hypermethylation changes were more supported by RRBS than hypomethylation changes. Because all the arbitrarily chosen hypomethylated DMRs were successfully confirmed by independent qPCR (Fig. S3), the low rate of replication of hypomethylated DMRs by RRBS may support the involvement of other epigenetic regulations, such as $\mathrm{hmC}^{35}$ (see Discussion). Based on the DMRs confirmed by RRBS, typical DNA methylation differences were estimated to range from 12.4 to $17.8 \%$ (Table $\mathbf{S 7}$ ).

\section{Assessment of the effect of mood stabilizers}

We then assessed the effect of mood stabilizers on DNA methylation changes using a human neuroblastoma cell line. Cells cultured under the minimum and maximum therapeutic concentrations of three different mood stabilizers for 8 days were retrieved, and their DNA methylation patterns were profiled with the same array platform (Fig. 3a). We examined the relationship between the DMRs detected in BD patients and those detected in cell culture. We found that $31.3 \%$ and $37.9 \%$ of the neuronal and nonneuronal DMRs, respectively, overlapped with DMRs detected in at least one cell culture condition (Fig. 3b, Tables S2 and S3 for details of overlapping DMRs). Regarding the direction of methylation changes in the DMRs, both directions showed a similar extent of overlap (Fig. 3b). Further analysis revealed that hypomethylated DMRs in BD patients showed a greater overlap with hypermethylated DMRs in cell culture and vice versa among both neuronal DMRs (Fig. 3c) and nonneuronal DMRs (Fig. 3d). 


\section{Overlap analysis with a GWAS of BD}

We compared the chromosomal loci identified by a GWAS of BD with the DMRs. Among the 30 loci identified by the largest GWAS of $\mathrm{BD}^{6}, 8$ loci included a total of 12 DMRs (Fig. 4a). At the gene level, we also identified additional overlapping genes between the results of the GWAS and those of this study, including CACNA1C, SHANK2, and GRIN2A (Fig. 4b).

\section{qPCR of DNA methylation-related genes}

To examine the genes involved in the DNA methylation changes in $\mathrm{BD}$, we measured the gene expression levels of 4 DNA methyltransferases and 5 methyl-CpG binding domain-containing proteins by qRT-PCR using bulk PFC samples (Fig. 5a). Among the measured genes, the expression of DNMT3B, which is highly expressed in neurons, showed an increase compared to that in controls by using the multiple internal control genes for normalization and by $\mathrm{pH}$-adjusted analyses (Fig. 5b). Specific and increased expression of DNMT3B was also found in the PFC of SZ patients (Fig. 5b), suggesting that $D N M T 3 B$ is involved in altered DNA methylation in psychosis.

\section{Discussion}

Here, we performed brain cell type-specific DNA methylation analysis on the PFC of BD patients. Our analysis revealed a tendency towards decreased promoter methylation of both neurons and nonneurons and neuronal hypermethylation in some key genes important for neuronal function in $\mathrm{BD}$.

We employed the enrichment of methylated DNA by MBD2B/3L followed by 
promoter tiling array analysis. Compared to the bisulfite sequencing (BS)-based method, this approach has limitations in the coverage of the genome and accuracy of quantitative determination. However, taking advantage of the binding specificity of MBD2B, which does not bind hydroxymethylcytosine $(\mathrm{hmC})^{35}$, we were able to enrich and analyze the MRs consisting of methylcytosine $(\mathrm{mC})^{36,37}$. Excluding hmC would be particularly important because $\mathrm{hmC}$ is enriched in neurons and cannot be discriminated from $\mathrm{mC}$ by the $\mathrm{BS}^{19}$, which was supported by the failure to replicate hypomethylated sites by bisulfite sequencing in this study. Therefore, the DMRs defined based on only the mC will be valuable for interpretation of epigenetic signatures in the brain. By performing promoter-wide analysis, we focused on the genomic regions directly important for gene expression regulation. Genome-wide analysis, such as MBD-Seq, would be useful for future studies to understand the entire role of epigenetic regulation in BD. Another limitation would be that due to the enrichment-based method, it cannot estimate the methylation level by calculating the ratio of methylated to unmethylated signals. However, the accuracy of quantification has also been proven in MBD-Seq by using the appropriate reference $\operatorname{set}^{36}$. Although we could not adopt such correction in this study, we determined DMRs by independent duplicate assays, and we estimated that the DMRs showed substantial DNA methylation changes by RRBS analysis of the selected samples (Table S7).

\section{DNA hypomethylation in BD}

In control brains, we replicated the decreased number of neuronal MRs compared to nonneuronal $\mathrm{MRs}^{18}$. On the other hand, previous BS analyses by others reported higher methylated levels in neurons than in nonneurons ${ }^{19,23}$. Discordance may come from 
differences in the data interpretation involving higher hmC levels in neurons and in the genomic region analyzed in this study, i.e., promoters in this study and the entire genomic region in other studies. hmC may also affect the lower validation rate of hypomethylated DMRs by RRBS (Table S7). The global tendency toward hypomethylation and gene-specific neuronal hypermethylation in BD was seemingly contradictory. Although the molecular mechanism and relationship between these changes are unclear, such changes have also been observed in cancer cells ${ }^{38}$.

Global DNA hypomethylation is frequently reported in blood cells of psychiatric disorders, including $\mathrm{BD}^{39-41}$. We also reported global DNA hypomethylation in BD and SZ in blood cells, and hypomethylation was associated with the serum level of the methyl-group donor betaine $(N, N, N \text {-trimethylglycine })^{42}$. Whether hypomethylation in the PFC of BD patients is accompanied by similar metabolite changes remains unclear. Systematic DNA methylation changes across different tissues have been reported during normal aging, enabling the establishment of the epigenetic clock $^{43}$. Interestingly, BD patients showed accelerated aging in blood and brain tissues ${ }^{44}$, 45. It would be interesting to pursue the relationship between promoter-wide hypomethylation and accelerated aging in BD.

\section{DMR-associated genes}

By GO analysis, we found that motor activity-related terms were enriched in DMR-associated genes. Most of them showed hypomethylated changes in neurons (Fig. 2b). Genes included seven kinesin complex genes (KIFs and KLC3), six myosin components (MYHs and MYOs), one lipid transfer protein (STARD9), and two dynein complexes (DNAH17 and DNAH10), suggesting that motor molecules in neurons are 
widely dysregulated. Because neurons must transport synaptic vesicle precursors, neurotransmitter receptors, and mRNAs over long distances ${ }^{46}$, dysregulation of motor activity affects diverse neuronal functions and the pathophysiology of psychiatric disorders. Interestingly, altered microtubule functions in neural stem and mature neural cells in BD have been recently reported ${ }^{47}$.

We found hypermethylation of growth cone- and dendrite-related genes. Among them, NTRK2 and GRIN1 have been the long-studied genes in psychiatric disorders, and their downregulation in the postmortem brains of BD patients has been established. NTRK2, also known as TrkB, encodes a BDNF receptor and has been one of the prime targets in mood disorders. Decreased expression of NTRK2 was repeatedly reported in postmortem brains of patients with psychiatric disorders ${ }^{48-51}$ and animal models of depression ${ }^{52-54}$. The BDNF-NTRK2 signaling pathway is critical for the antidepressant effect of lamotorigine $\mathrm{e}^{55}$ and ketamine $\mathrm{e}^{56,57}$ as well as the antimanic effect of lithium ${ }^{58}$ in animal models. Genetic studies have revealed that NTRK2 is associated with the treatment response to mood stabilizers in $\mathrm{BD}^{59,60}$ and suicidal behavior in mood disorders ${ }^{61}$. Interestingly, hypermethylation of the $\mathrm{CpG}$ island of the NTRK2 promoter has been reported in suicide completers ${ }^{62}$. Because the identified region in this study was close to the $\mathrm{CpG}$ island, these methylation changes may be linked and contribute to the pathophysiology of psychiatric disorders.

NMDA receptors (NMDARs) mediate basic neuronal functions, and their dysfunction is closely linked to the pathophysiology of psychiatric disorders ${ }^{63}$. GRIN1 $(N R I)$ encodes an essential subunit of NMDAR, and its downregulation was reported in the postmortem brains of patients with psychiatric disorders ${ }^{64}$. GRIN1 knockdown mice showed a wide range of behavioral alterations related to psychiatric disorders ${ }^{65}$. The 
involvement of altered DNA methylation of NMDAR genes, including $N R l$, which is associated with changes in expression and subunit composition, has been reported ${ }^{66-68}$.

Other characteristic findings include a wide range of DNA methylation changes in ion channel- and transporter-related genes in nonneurons. For example, they include four calcium channels (CACNA1C, CACNA2D4, CACNB2, and CACNG8), three glutamate receptors (GRIK2, GRIN2A, and GRM8), four GABA receptors (GABRA5, GABRG3, GABRG3, and GABRP), and nine potassium channels (KCNA1, KCNA4, KCNA7, KCNAB2, KCNAB2, KCND3, KCND3, KCNE1, and $K C N G 2)$. A recent GWAS showed enrichment of GWAS signals in calcium signaling genes and genes expressed in neurons ${ }^{69}$. The current finding of DNA methylation changes in ion channels, including calcium channels, sheds light on the potential roles of these channels in nonneurons, such as oligodendrocytes, microglia, and astrocytes, in BD. Further analysis of the specific nonneuronal cell population will be important.

\section{Effect of mood stabilizers on epigenetic alterations}

We observed that up to $37.9 \%$ of DMRs in BD overlapped with mood stabilizer-induced DMRs in cultured cells (Fig. 3b). Despite the simple cell culture model, these overlapping DMRs and opposite directions of changes between the postmortem brain and cell culture imply the pathophysiological importance of these DMRs. A similar opposite direction of DNA methylation changes related to mood stabilizers has been reported not only in a gene-specific manner ${ }^{26}$ but also in systematic alterations in accelerated aging in $\mathrm{BD}^{70}$. Although the precise molecular mechanism remains unclear, mood stabilizers can normalize epigenetic regulation in brain cells ${ }^{12}$, leading to the amelioration of multiple DMRs between BD patients and controls. 


\section{Comparison with GWAS results}

At the chromosomal location level, among the DMRs overlapping between GWAS and this study, we regarded KMT2E and SPTBN2 as particularly important (Fig. 4a). $K M T 2 E$ encodes histone lysine methyltransferase $2 \mathrm{E}$. Loss of function of histone lysine methyltransferases is involved in BD, SZ, and autism ${ }^{8,71,72}$, and cell-type-specific alteration of histone lysine modification in postmortem brains and animal models of psychiatric disorders has been reported $^{73}$. SPTBN2, also known as SCA5, regulates glutamate signaling by stabilizing EAAT4, and mutations in SPTBN2 cause spinocerebellar ataxia type $5^{74}$. At the gene level, several genes overlapped with GWAS, including the well-studied genes in $\mathrm{BD}^{6}$ such as CACNAIC, SHANK2, and GRIN2A (Fig. 4b). They seemed to appear as candidates due to their long gene length. Taken together, epigenetic alterations of GWAS-implicated genes provide important insights into the molecular pathophysiology of BD. The relationship between risk SNPs and DNA methylation status will be an important issue to be studied.

\section{Overexpression of $\mathrm{DNMT3B}$ in $\mathrm{BD}$ and $\mathrm{SZ}$}

The role of DNA methylation-related genes, especially DNMT1, in BD and SZ has been well studied $^{12}$. In this study, we found an increase in DNMT3B expression in both BD and SZ, implicating the possible role of $D N M T 3 B$ in neuronal hypermethylation in BD (Fig. 5). Whether patients with SZ show epigenetic changes similar to those of patients with BD needs to be studied. Increased expression of DNMT3B, but not DNMT1 and DNMT3A, was recently reported in learned helplessness rats, supporting its role as a stress-inducible, psychiatric disorder-related neuronal DNA methyltransferase ${ }^{75}$. 
However, the molecular mechanism underlying DNMT3B overexpression and gene-specific neuronal hypermethylation remains unknown. Additionally, the examination of genes responsible for the cytosine modification pathway, such as the TET family, base-excision repair genes and methyl-donor metabolism-related genes, would be considered candidate genes potentially involved in epigenetic dysregulation in BD.

\section{Conclusion}

We observed cell-type-specific, pathophysiology-related DNA methylation changes in the PFC of patients with BD and identified increased expression of DNMT3B as a potential molecular mechanism. The present findings may help in understanding the neurobiological mechanisms underlying bipolar disorder.

\section{Acknowledgments}

This work was supported in part by the UTokyo Center for Integrative Science of Human Behavior (CiSHuB) and by the International Research Center for Neurointelligence (WPI-IRCN) at The University of Tokyo Institutes for Advanced Study (UTIAS). Postmortem brains were donated by the Stanley Microarray Collection, courtesy of Drs Michael B. Knable, E. Fuller Torrey, Maree J. Webster, and Robert H. Yolken. We are indebted to the Research Resource Center at the RIKEN for nuclear sorting and microarray analysis. We would like to thank Taeko Miyauchi and Fumiko Sunaga for their technical assistance.

\section{Conflict of interest}


medRxiv preprint doi: https://doi.org/10.1101/2020.12.10.20246405; this version posted December 11, 2020. The copyright holder for this preprint (which was not certified by peer review) is the author/funder, who has granted medRxiv a license to display the preprint in perpetuity. It is made available under a CC-BY-NC-ND 4.0 International license .

None declared.

\section{Grant information}

The work was partly supported by JSPS KAKENHI Grant Numbers: 16H06395, 16H06399, 18H05435, 16K21720, 18H05428, 18H02753, 18H05430, and 18K07567.

This research was also partly supported by AMED under Grant Numbers

JP15gm0510002, JP20dm0307001, JP20dm0307004, JP20dm0207069, JP20dm0107123, JP20dm0207074, and JP20km0405208. 


\section{References}

1. Grande I, Berk M, Birmaher B, Vieta E. Bipolar disorder. Lancet 2016; 387(10027): $1561-1572$.

2. Kato T. Current understanding of bipolar disorder: Toward integration of biological basis and treatment strategies. Psychiatry Clin Neurosci 2019; 73(9): 526-540.

3. McGuffin P, Rijsdijk F, Andrew M, Sham P, Katz R, Cardno A. The heritability of bipolar affective disorder and the genetic relationship to unipolar depression. Arch Gen Psychiatry 2003; 60(5): 497-502.

4. Cross-Disorder Group of the Psychiatric Genomics C, Lee SH, Ripke S, Neale BM, Faraone SV, Purcell SM et al. Genetic relationship between five psychiatric disorders estimated from genome-wide SNPs. Nature genetics 2013; 45(9): 984-994.

5. Purcell SM, Wray NR, Stone JL, Visscher PM, O'Donovan MC, Sullivan PF et al. Common polygenic variation contributes to risk of schizophrenia and bipolar disorder. Nature 2009; 460(7256): 748-752.

6. Stahl EA, Breen G, Forstner AJ, McQuillin A, Ripke S, Trubetskoy V et al. Genome-wide association study identifies 30 loci associated with bipolar disorder. Nature genetics 2019; 51(5): 793-803.

7. Goes FS, Pirooznia M, Tehan M, Zandi PP, McGrath J, Wolyniec P et al. De novo variation in bipolar disorder. Mol Psychiatry 2019.

8. Kataoka M, Matoba N, Sawada T, Kazuno AA, Ishiwata M, Fujii K et al. Exome sequencing for bipolar disorder points to roles of de novo loss-of-function and protein-altering mutations. Mol Psychiatry 2016; 21(7): 885-893.

9. Malhotra D, McCarthy S, Michaelson JJ, Vacic V, Burdick KE, Yoon S et al. High Frequencies of De Novo CNVs in Bipolar Disorder and Schizophrenia. Neuron 2011; 72(6): 951-963.

10. Feinberg AP. Phenotypic plasticity and the epigenetics of human disease. Nature 2007; 447(7143): 433-440. 
11. Nestler EJ, Pena CJ, Kundakovic M, Mitchell A, Akbarian S. Epigenetic Basis of Mental Illness. Neuroscientist 2016; 22(5): 447-463.

12. Fries GR, Li Q, McAlpin B, Rein T, Walss-Bass C, Soares JC et al. The role of DNA methylation in the pathophysiology and treatment of bipolar disorder. Neuroscience and biobehavioral reviews 2016; 68: 474-488.

13. Richetto J, Meyer U. Epigenetic Modifications in Schizophrenia and Related Disorders: Molecular Scars of Environmental Exposures and Source of Phenotypic Variability. Biol Psychiatry 2020.

14. Chen C, Zhang C, Cheng L, Reilly JL, Bishop JR, Sweeney JA et al. Correlation between DNA methylation and gene expression in the brains of patients with bipolar disorder and schizophrenia. Bipolar Disord 2014; 16(8): 790-799.

15. Fries GR, Bauer IE, Scaini G, Valvassori SS, Walss-Bass C, Soares JC et al. Accelerated hippocampal biological aging in bipolar disorder. Bipolar Disord 2019.

16. Abdolmaleky HM, Gower AC, Wong CK, Cox JW, Zhang X, Thiagalingam A et al. Aberrant transcriptomes and DNA methylomes define pathways that drive pathogenesis and loss of brain laterality/asymmetry in schizophrenia and bipolar disorder. Am J Med Genet B Neuropsychiatr Genet 2019; 180(2): 138-149.

17. Ho AM, Winham SJ, Armasu SM, Blacker CJ, Millischer V, Lavebratt C et al. Genome-wide DNA methylomic differences between dorsolateral prefrontal and temporal pole cortices of bipolar disorder. J Psychiatr Res 2019; 117: 45-54.

18. Iwamoto K, Bundo M, Ueda J, Oldham MC, Ukai W, Hashimoto E et al. Neurons show distinctive DNA methylation profile and higher interindividual variations compared with non-neurons. Genome Res 2011; 21(5): 688-696.

19. Lister R, Mukamel EA, Nery JR, Urich M, Puddifoot CA, Johnson ND et al. Global epigenomic reconfiguration during mammalian brain development. Science 2013; 341(6146): 1237905. 
20. Kozlenkov A, Wang M, Roussos P, Rudchenko S, Barbu M, Bibikova M et al. Substantial DNA methylation differences between two major neuronal subtypes in human brain. Nucleic Acids Res 2016; 44(6): 2593-2612.

21. Girdhar K, Hoffman GE, Jiang Y, Brown L, Kundakovic M, Hauberg ME et al. Cell-specific histone modification maps in the human frontal lobe link schizophrenia risk to the neuronal epigenome. Nature neuroscience 2018; 21(8): 1126-1136.

22. Mendizabal I, Berto S, Usui N, Toriumi K, Chatterjee P, Douglas C et al. Cell type-specific epige netic links to schizophrenia risk in the brain. Genome Biol 2019; 20(1): 135 .

23. Rizzardi LF, Hickey PF, Rodriguez DiBlasi V, Tryggvadottir R, Callahan CM, Idrizi A et al. Neuronal brain-region-specific DNA methylation and chromatin accessibility are associated with neuropsychiatric trait heritability. Nature neuroscience 2019; 22(2): 307-316.

24. Gusev FE, Reshetov DA, Mitchell AC, Andreeva TV, Dincer A, Grigorenko AP et al. Chromatin profiling of cortical neurons identifies individual epigenetic signatures in schizophrenia. Transl Psychiatry 2019; 9(1): 256.

25. Pai S, Li P, Killinger B, Marshall L, Jia P, Liao J et al. Differential methylation of enhancer at IGF2 is associated with abnormal dopamine synthesis in major psychosis. Nat Commun 2019; 10(1): 2046.

26. Asai T, Bundo M, Sugawara H, Sunaga F, Ueda J, Tanaka G et al. Effect of mood stabilizers on DNA methylation in human neuroblastoma cells. The international journal of neuropsychopharmacology / official scientific journal of the Collegium Internationale Neuropsychopharmacologicum 2013: 1-10.

27. Johnson WE, Li W, Meyer CA, Gottardo R, Carroll JS, Brown M et al. Model-based analysis of tiling-arrays for ChIP-chip. Proceedings of the National Academy of Sciences of the United States of America 2006; 103(33): 12457-12462.

28. Quinlan AR, Hall IM. BEDTools: a flexible suite of utilities for comparing genomic features. Bioinformatics 2010; 26(6): 841-842. 
29. Heinz S, Benner C, Spann N, Bertolino E, Lin YC, Laslo P et al. Simple combinations of lineage-determining transcription factors prime cis-regulatory elements required for macrophage and B cell identities. Mol Cell 2010; 38(4): 576-589.

30. Chen J, Bardes EE, Aronow BJ, Jegga AG. ToppGene Suite for gene list enrichment analysis and candidate gene prioritization. Nucleic Acids Res 2009; 37(Web Server issue): W305-311.

31. Nakachi Y, Ishii K, Bundo M, Masuda T, Iwamoto K. Use of the Illumina EPIC methylation array for epigenomic research in the crab-eating macaque (Macaca fascicularis). Neuropsychopharmacol Rep 2020.

32. Iwamoto K, Kakiuchi C, Bundo M, Ikeda K, Kato T. Molecular characterization of bipolar disorder by comparing gene expression profiles of postmortem brains of major mental disorders. Mol Psychiatry 2004; 9(4): 406-416.

33. Tomita H, Vawter MP, Walsh DM, Evans SJ, Choudary PV, Li J et al. Effect of agonal and postmortem factors on gene expression profile: quality control in microarray analyses of postmortem human brain. Biol Psychiatry 2004; 55(4): 346-352.

34. Iwamoto K, Bundo M, Kato T. Altered expression of mitochondria-related genes in postmortem brains of patients with bipolar disorder or schizophrenia, as revealed by large-scale DNA microarray analysis. Hum Mol Genet 2005; 14(2): 241-253.

35. Jin SG, Kadam S, Pfeifer GP. Examination of the specificity of DNA methylation profiling techniques towards 5-methylcytosine and 5-hydroxymethylcytosine. Nucleic Acids Res 2010; 38(11): e125.

36. Aberg KA, Chan RF, van den Oord E. MBD-seq - realities of a misunderstood method for high-quality methylome-wide association studies. Epigenetics 2020; 15(4): 431-438.

37. Chan RF, Shabalin AA, Xie LY, Adkins DE, Zhao M, Turecki G et al. Enrichment methods provide a feasible approach to comprehensive and adequately powered 
investigations of the brain methylome. Nucleic Acids Res 2017; 45(11): e97.

38. Ehrlich M. DNA hypomethylation in cancer cells. Epigenomics 2009; 1(2): 239-259.

39. Melas PA, Rogdaki M, Osby U, Schalling M, Lavebratt C, Ekstrom TJ. Epigenetic aberrations in leukocytes of patients with schizophrenia: association of global DNA methylation with antipsychotic drug treatment and disease onset. FASEB J2012; 26(6): 2712-2718.

40. Huzayyin AA, Andreazza AC, Turecki G, Cruceanu C, Rouleau GA, Alda M et al. Decreased global methylation in patients with bipolar disorder who respond to lithium. The international journal of neuropsychopharmacology / official scientific journal of the Collegium Internationale Neuropsychopharmacologicum 2014; 17(4): 561-569.

41. Li S, Yang Q, Hou Y, Jiang T, Zong L, Wang Z et al. Hypomethylation of LINE-1 elements in schizophrenia and bipolar disorder. J Psychiatr Res 2018; 107: 68-72.

42. Murata Y, Ikegame T, Koike S, Saito T, Ikeda M, Sasaki T et al. Global DNA hypomethylation and its correlation to the betaine level in peripheral blood of patients with schizophrenia. Prog Neuropsychopharmacol Biol Psychiatry 2020; 99: 109855 .

43. Horvath S. DNA methylation age of human tissues and cell types. Genome Biol 2013; 14(10): R115.

44. Fries GR, Zamzow MJ, Andrews T, Pink O, Scaini G, Quevedo J. Accelerated aging in bipolar disorder: A comprehensive review of molecular findings and their clinical implications. Neuroscience and biobehavioral reviews 2020; 112: 107-116.

45. Fries GR, Zamzow MJ, Colpo GD, Monroy-Jaramillo N, Quevedo J, Arnold JG et al. The anti-aging effects of lithium in lymphoblastoid cell lines from patients with bipolar disorder and controls. J Psychiatr Res 2020; 128: 38-42.

46. Hirokawa N, Niwa S, Tanaka Y. Molecular motors in neurons: transport mechanisms and roles in brain function, development, and disease. Neuron 2010; 
68(4): 610-638.

47. Truve K, Parris TZ, Vizlin-Hodzic D, Salmela S, Berger E, Agren H et al. Identification of candidate genetic variants and altered protein expression in neural stem and mature neural cells support altered microtubule function to be an essential component in bipolar disorder. Transl Psychiatry 2020; 10(1): 390.

48. Dwivedi Y, Rizavi HS, Conley RR, Roberts RC, Tamminga CA, Pandey GN. Altered gene expression of brain-derived neurotrophic factor and receptor tyrosine kinase $\mathrm{B}$ in postmortem brain of suicide subjects. Arch Gen Psychiatry 2003; 60(8): 804-815.

49. Weickert CS, Ligons DL, Romanczyk T, Ungaro G, Hyde TM, Herman MM et al. Reductions in neurotrophin receptor mRNAs in the prefrontal cortex of patients with schizophrenia. Mol Psychiatry 2005; 10(7): 637-650.

50. Reinhart V, Bove SE, Volfson D, Lewis DA, Kleiman RJ, Lanz TA. Evaluation of TrkB and BDNF transcripts in prefrontal cortex, hippocampus, and striatum from subjects with schizophrenia, bipolar disorder, and major depressive disorder. Neurobiology of disease 2015; 77: 220-227.

51. Ray MT, Shannon Weickert C, Webster MJ. Decreased BDNF and TrkB mRNA expression in multiple cortical areas of patients with schizophrenia and mood disorders. Transl Psychiatry 2014; 4: e389.

52. Bai YY, Ruan CS, Yang CR, Li JY, Kang ZL, Zhou L et al. ProBDNF Signaling Regulates Depression-Like Behaviors in Rodents under Chronic Stress.

Neuropsychopharmacology : official publication of the American College of Neuropsychopharmacology 2016; 41(12): 2882-2892.

53. Givalois L, Marmigere F, Rage F, Ixart G, Arancibia S, Tapia-Arancibia L. Immobilization stress rapidly and differentially modulates BDNF and TrkB mRNA expression in the pituitary gland of adult male rats. Neuroendocrinology 2001; 74(3): 148-159.

54. Sales AJ, Maciel IS, Suavinha A, Joca SRL. Modulation of DNA Methylation and Gene Expression in Rodent Cortical Neuroplasticity Pathways Exerts Rapid 
Antidepressant-Like Effects. Mol Neurobiol 2020.

55. Li N, He X, Zhang Y, Qi X, Li H, Zhu X et al. Brain-derived neurotrophic factor signalling mediates antidepressant effects of lamotrigine. The international journal of neuropsychopharmacology / official scientific journal of the Collegium

Internationale Neuropsychopharmacologicum 2011; 14(8): 1091-1098.

56. Hashimoto K. Brain-derived neurotrophic factor-TrkB signaling and the mechanism of antidepressant activity by ketamine in mood disorders. Eur Arch Psychiatry Clin Neurosci 2020; 270(2): 137-138.

57. Bjorkholm C, Monteggia LM. BDNF - a key transducer of antidepressant effects. Neuropharmacology 2016; 102: 72-79.

58. Gideons ES, Lin PY, Mahgoub M, Kavalali ET, Monteggia LM. Chronic lithium treatment elicits its antimanic effects via BDNF-TrkB dependent synaptic downscaling. Elife 2017; 6.

59. Wang Z, Fan J, Gao K, Li Z, Yi Z, Wang L et al. Neurotrophic tyrosine kinase receptor type 2 (NTRK2) gene associated with treatment response to mood stabilizers in patients with bipolar I disorder. J Mol Neurosci 2013; 50(2): 305-310.

60. Fabbri C, Serretti A. Genetics of long-term treatment outcome in bipolar disorder. Prog Neuropsychopharmacol Biol Psychiatry 2016; 65: 17-24.

61. Pulay AJ, Rethelyi JM. Multimarker analysis suggests the involvement of BDNF signaling and microRNA biosynthesis in suicidal behavior. Am J Med Genet B Neuropsychiatr Genet 2016; 171(6): 763-776.

62. Ernst C, Deleva V, Deng X, Sequeira A, Pomarenski A, Klempan T et al. Alternative splicing, methylation state, and expression profile of tropomyosin-related kinase B in the frontal cortex of suicide completers. Arch Gen Psychiatry 2009; 66(1): 22-32.

63. Coyle JT, Balu DT, Puhl MD, Konopaske GT. History of the Concept of Disconnectivity in Schizophrenia. Harv Rev Psychiatry 2016; 24(2): 80-86. 
64. Catts VS, Lai YL, Weickert CS, Weickert TW, Catts SV. A quantitative review of the postmortem evidence for decreased cortical N-methyl-D-aspartate receptor expression levels in schizophrenia: How can we link molecular abnormalities to mismatch negativity deficits? Biol Psychol 2016; 116: 57-67.

65. Mielnik CA, Binko MA, Chen Y, Funk AJ, Johansson EM, Intson K et al. Consequences of NMDA receptor deficiency can be rescued in the adult brain. $\mathrm{Mol}$ Psychiatry 2020.

66. Snyder MA, Gao WJ. NMDA receptor hypofunction for schizophrenia revisited: Perspectives from epigenetic mechanisms. Schizophr Res 2020; 217: 60-70.

67. Gulchina Y, Xu SJ, Snyder MA, Elefant F, Gao WJ. Epigenetic mechanisms underlying NMDA receptor hypofunction in the prefrontal cortex of juvenile animals in the MAM model for schizophrenia. Journal of neurochemistry 2017; 143(3): 320-333.

68. Loureiro CM, Fachim HA, Corsi-Zuelli F, Shuhama R, Joca S, Menezes PR et al. Epigenetic-mediated N-methyl-D-aspartate receptor changes in the brain of isolated reared rats. Epigenomics 2020.

69. Mullins N, Forstner AJ, O'Connell KS, Coombes B, Coleman JRI, Qiao Z et al. Genome-wide association study of over 40,000 bipolar disorder cases provides novel biological insights. medRxiv 2020.

70. Okazaki S, Numata S, Otsuka I, Horai T, Kinoshita M, Sora I et al. Decelerated epigenetic aging associated with mood stabilizers in the blood of patients with bipolar disorder. Transl Psychiatry 2020; 10(1): 129.

71. Singh T, Kurki MI, Curtis D, Purcell SM, Crooks L, McRae J et al. Rare loss-of-function variants in SETD1A are associated with schizophrenia and developmental disorders. Nature neurascience 2016; 19(4): 571-577.

72. Takata A, Ionita-Laza I, Gogos JA, Xu B, Karayiorgou M. De Novo Synonymous Mutations in Regulatory Elements Contribute to the Genetic Etiology of Autism and Schizophrenia. Neuron 2016; 89(5): 940-947. 
medRxiv preprint doi: https://doi.org/10.1101/2020.12.10.20246405; this version posted December 11, 2020. The copyright holder for this preprint (which was not certified by peer review) is the author/funder, who has granted medRxiv a license to display the preprint in perpetuity.

It is made available under a CC-BY-NC-ND 4.0 International license .

73. Jiang Y, Loh YE, Rajarajan P, Hirayama T, Liao W, Kassim BS et al. The methyltransferase SETDB1 regulates a large neuron-specific topological chromatin domain. Nature genetics 2017; 49(8): 1239-1250.

74. Ikeda Y, Dick KA, Weatherspoon MR, Gincel D, Armbrust KR, Dalton JC et al. Spectrin mutations cause spinocerebellar ataxia type 5. Nature genetics 2006; 38(2): 184-190.

75. de Sousa Maciel I, Sales AJ, Casarotto PC, Castren E, Biojone C, Joca SRL. Nitric Oxide Synthase inhibition counteracts the stress-induced DNA methyltransferase 3b expression in the hippocampus of rats. Eur J Neurosci 2020. 


\section{Figure Legends}

Figure 1. MRs and DMRs in BD. a. PCA of the MRs of each sample. b. Decreased number of MRs in BD. * shows significant changes by the Mann-Whitney test. c. Chromosomal locations of DMRs. d. Total number of DMRs and DMR-associated genes. e. Venn diagrams of DMR-associated genes. Detailed information on DMRs is shown in Tables S2 and S3. MR, methylated region; DMRs, differentially methylated regions; BD, bipolar disorder; PCA, principal component analysis; CT, control.

Figure 2. GO analysis of DMRs. a. GO analysis of all DMR-associated genes. Significant GO terms were sorted based on the ascending order of the percentage of NeuN+ DMR-associated genes. See Table $\mathbf{S 4}$ for detailed results. b. GO analysis of DMR-associated genes considering the cell type and direction of methylation changes. Only the results of neuronal DMR-associated genes are presented. See Table S5 for the results of nonneurons. c Example of neuronal hypermethylation at GRIN1 and NTRK2. DMRs are denoted by black squares. The top panel shows DNA methylation levels determined by direct comparison of $\mathrm{BD}(\mathrm{N}=34)$ and $\mathrm{CT}(\mathrm{N}=35)$ samples. The peaks for the target group (BD) are shown to highlight the DMR. The bottom panels show average DNA methylation levels determined by comparison of either $\mathrm{CT}(\mathrm{N}=35)$ or $\mathrm{BD}(\mathrm{N}=34)$ with references (nonmethylated human genome). GO, gene ontology; DMRs, differentially methylated regions; CT, control; BD, bipolar disorder; MR, methylated region. 
Figure 3. Effect of mood stabilizers on DMRs. a. Experimental scheme for cell culture. b. \% overlap with drug-induced DMRs. Detailed analysis of the overlap between either neuronal DMRs (c) or nonneuronal DMRs (d) and drug-induced DMRs. The abbreviations max, min, and $(\max +\min )$ indicate maximum, minimum, and maximum or minimum therapeutic concentrations of mood stabilizers. * indicates a significant difference in Fisher's exact test $(\mathrm{P}<0.05)$. Detailed information on overlapping DMRs is shown in Tables S2 and S3. DMRs, differentially methylated regions; BD, bipolar disorder; Li, lithium; Val, valproate; Car, carbamazepine.

Figure 4. The overlap between GWAS loci and DMRs. a. Overlap at the chromosomal locus level (hg19). b. Overlap at the affected gene level. Genes indicated in red show that those DMRs are included in the GWAS loci. Note that the total number of DMR-associated genes shows some inconsistencies with Figure 1 due to the presence of genes having multiple DMRs of both directions of changes. GWAS loci and genes were retrieved from Stahl et $a l^{6}$. GWAS, genome-wide association study; DMRs, differentially methylated regions.

Figure 5. qRT-PCR analysis of DNA methylation-related genes. a. Expression levels of DNA methylation-related genes. Expression levels were plotted relative to the average value of the control. Note that for some subjects, total RNA samples were not available. b. The expression level of $D N M T 3 B$ in BD and SZ. The expression levels of two different genes, GAPDH: G and CFL1: C, were used as internal controls. In the $\mathrm{pH}$-adjusted analysis, samples for which the brain sample $\mathrm{pH}$ was below 6.4 were removed from the analysis based on a previous study. ${ }^{34} *$ indicates a significant change 
medRxiv preprint doi: https://doi.org/10.1101/2020.12.10.20246405; this version posted December 11, 2020. The copyright holder for this preprint (which was not certified by peer review) is the author/funder, who has granted medRxiv a license to display the preprint in perpetuity. It is made available under a CC-BY-NC-ND 4.0 International license .

in the Mann-Whitney test compared to the CT $(\mathrm{P}<0.05)$. CT, control; BD, bipolar disorder; SZ, schizophrenia 
medRxiv preprint doi: https://doi.org/10.1101/2020.12.10.20246405; this version posted December 11, 2020. The copyright holder for this preprint (which was not certified by peer review) is the author/funder, who has granted medRxiv a license to display the preprint in perpetuity.

It is made available under a CC-BY-NC-ND 4.0 International license . 
medRxiv preprint doi: https://doi.org/10.1101/2020.12.10.20246405; this version posted December 11, 2020. The copyright holder for this preprint (which was not certified by peer review) is the author/funder, who has granted medRxiv a license to display the preprint in perpetuity.

It is made available under a CC-BY-NC-ND 4.0 International license .

a

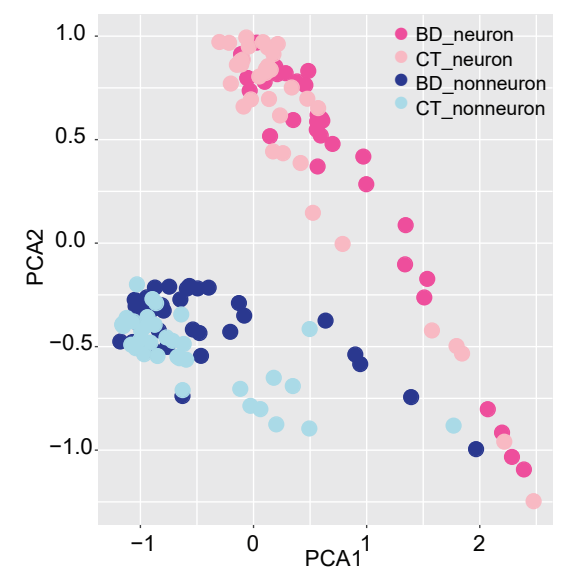

C

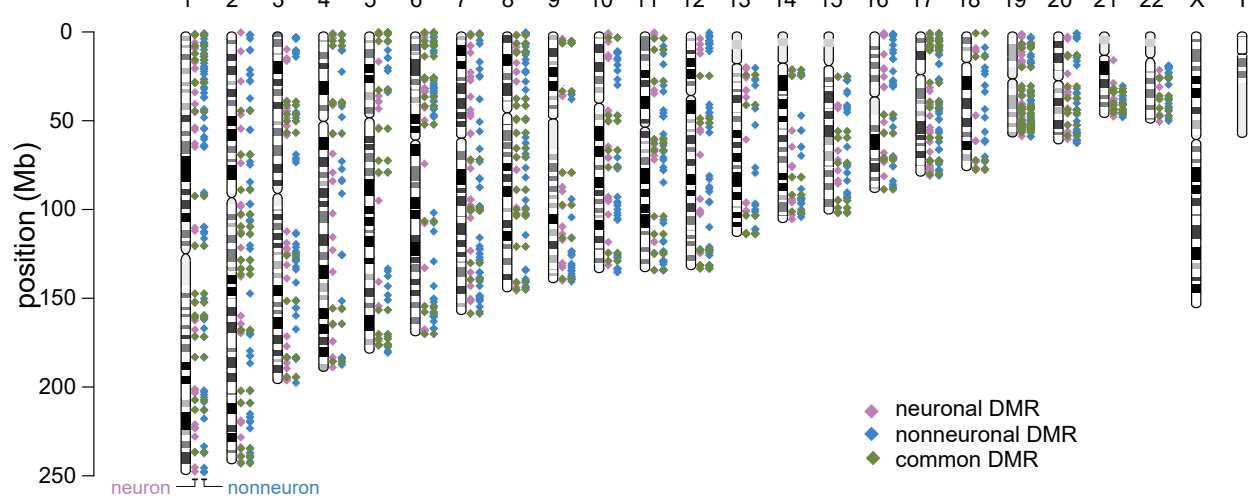

b $\square$ nonneuron $\square$ neuron

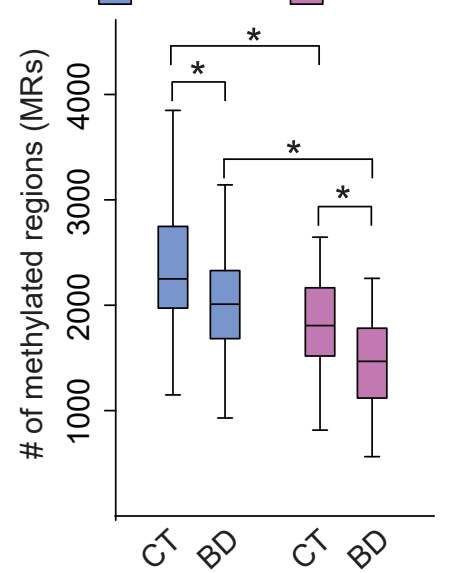

d

\begin{tabular}{lcc}
\hline & $\begin{array}{r}\text { hypomethylated } \\
\text { DMRs (genes) }\end{array}$ & $\begin{array}{c}\text { hypermethylated } \\
\text { DMRs (genes) }\end{array}$ \\
\hline neuron & $897(587)$ & $90(77)$ \\
nonneuron & $1224(892)$ & $72(56)$ \\
\hline
\end{tabular}

e

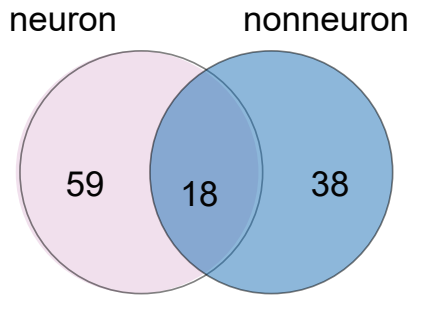

hypermethylated genes

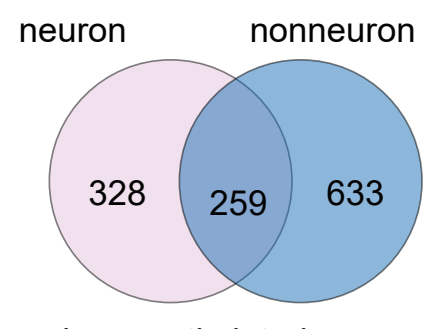

hypomethylated genes 
medRxiv preprint doi: https://doi.org/10.1101/2020.12.10.20246405; this version posted December 11, 2020. The copyright holder for this preprint (which was not certified by peer review) is the author/funder, who has granted medRxiv a license to display the preprint in perpetuity.

It is made available under a CC-BY-NC-ND 4.0 International license .

a

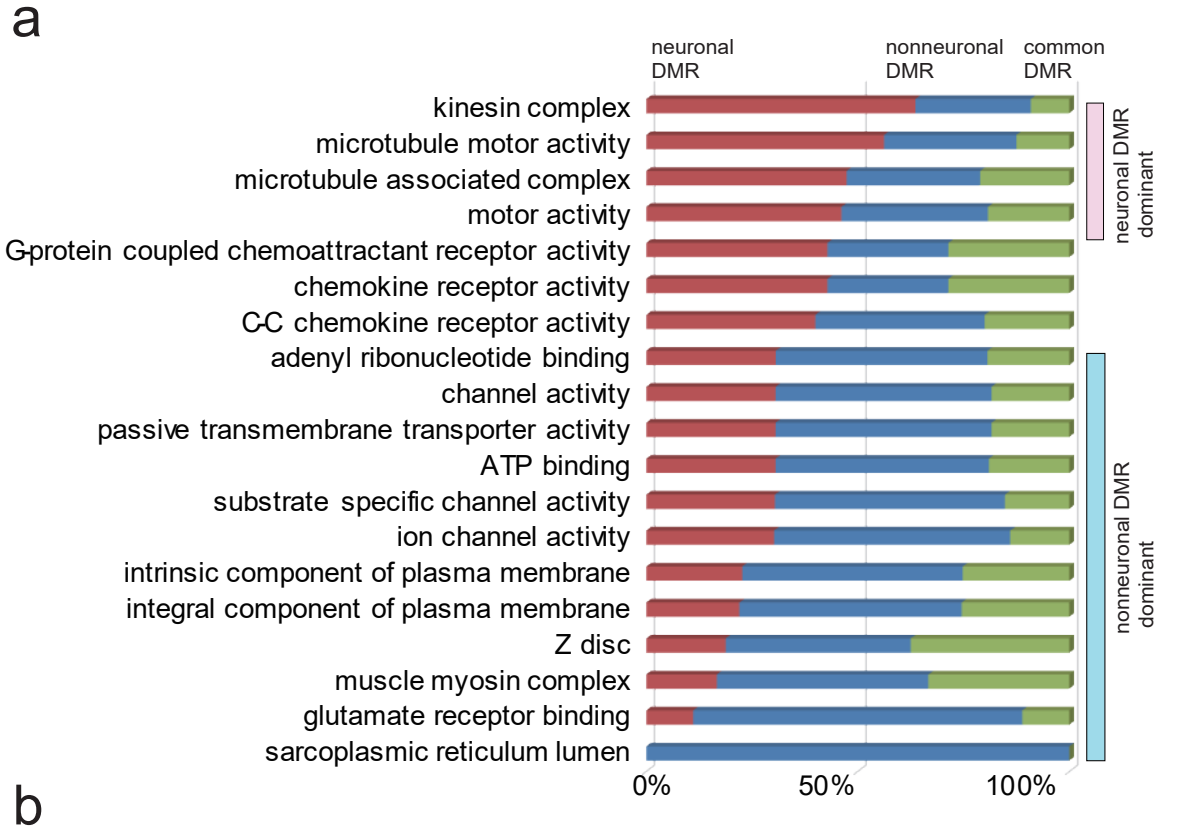

C

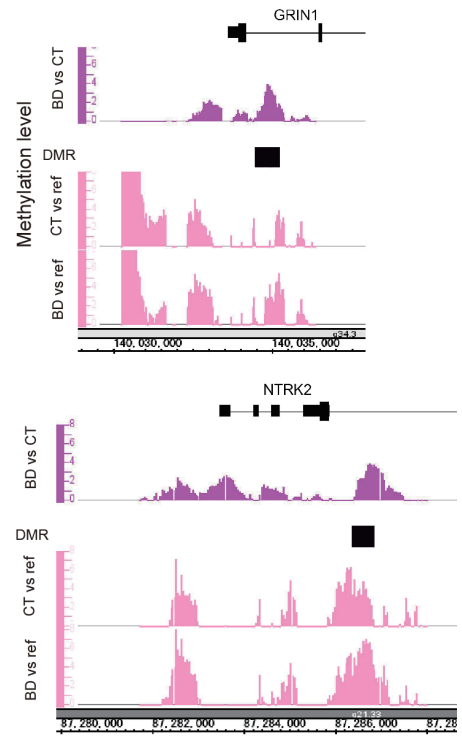
count $p$-value gene

neuronal hypermethylation GO:0030426 growth cone

5 1.72E-04 AMFR, NTRK2, PPP1R9A, SNX18, GRIN1

GO:0030427 site of polarized growth

GO:0005654 nucleoplasm

GO:0030425 dendrite

5 1.96E-04 AMFR, NTRK2, PPP1R9A, SNX18, GRIN1

GO:0097481 neuronal postsynaptic

14 7.31E-04 CIRBP, HIST1H2BJ, URI1, PPP3CA, MCPH1, INTS1, HMGB2, IRF2, RERE, MCM10, KMT2E, USP1,

MAP2K6, SAP30

7 1.60E-03 AMFR, URI1, PPT1, NTRK2, PPP1R9A, UHMK1, GRIN1

GO:0097481 density

2 2.17E-03 NTRK2, GRIN1 
medRxiv preprint doi: https://doi.org/10.1101/2020.12.10.20246405; this version posted December 11, 2020. The copyright holder for this preprint (which was not certified by peer review) is the author/funder, who has granted medRxiv a license to display the preprint in perpetuity.

a

SK-N-SH

(neuroblastoma)

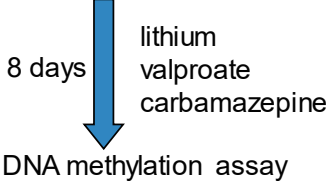

DNA methylation assay b
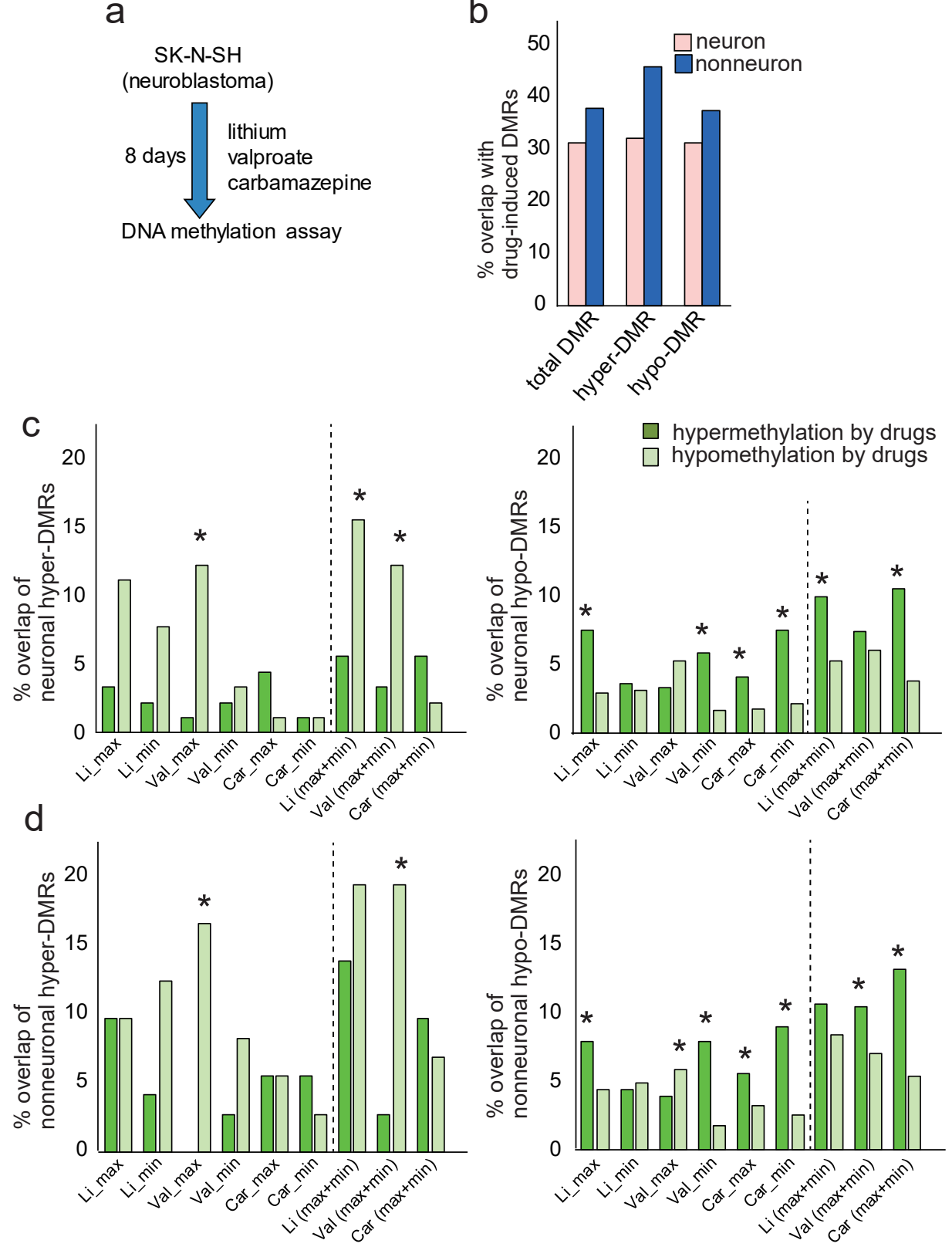
medRxiv preprint doi: https://doi.org/10.1101/2020.12.10.20246405; this version posted December 11, 2020. The copyright holder for this preprint (which was not certified by peer review) is the author/funder, who has granted medRxiv a license to display the preprint in perpetuity.

It is made available under a CC-BY-NC-ND 4.0 International license .

a

\begin{tabular}{llll}
\hline GWAS locus & DMR & gene & cell type, direction of change \\
\hline chr1:149998923-150470296 & chr1:150265164-150265927 & MRPS21 & nonneuron, hypomethylation \\
chr3:52220203-53101580 & chr3:52812330-52812953 & TIH1 & neuron, hypomethylation \\
& chr3:52823071-52824030 & TIH1 & neuron, hypomethylation \\
chr7:104576138-105048158 & chr7:104752415-104753476 & KMT2E & neuron, hypermethylation \\
chr11:65785739-66060538 & chr11:65792369-65794029 & CATSPER1 & neuron, hypomethylation \\
chr11:66143797-66673079 & chr11:66489135-66489758 & SPTBN2 & nonneuron, hypomethylation \\
chr15:42484890-43148042 & chr15:42944201-42944824 & STARD9 & neuron, hypomethylation \\
chr15:84703470-85425468 & chr15:85424419-85425260 & SLC28A1 & neuron, hypomethylation \\
chr19:19324806-19801607 & chr19:19446552-19447175 & MAU2 & nonneuron, hypomethylation \\
& chr19:19744949-19745572 & GMIP & neuron, hypomethylation \\
& chr19:19789731-19791286 & ZNF101 & nonneuron, hypomethylation \\
& chr19:19789978-19791101 & ZNF101 & neuron, hypomethylation \\
\hline & & &
\end{tabular}

b

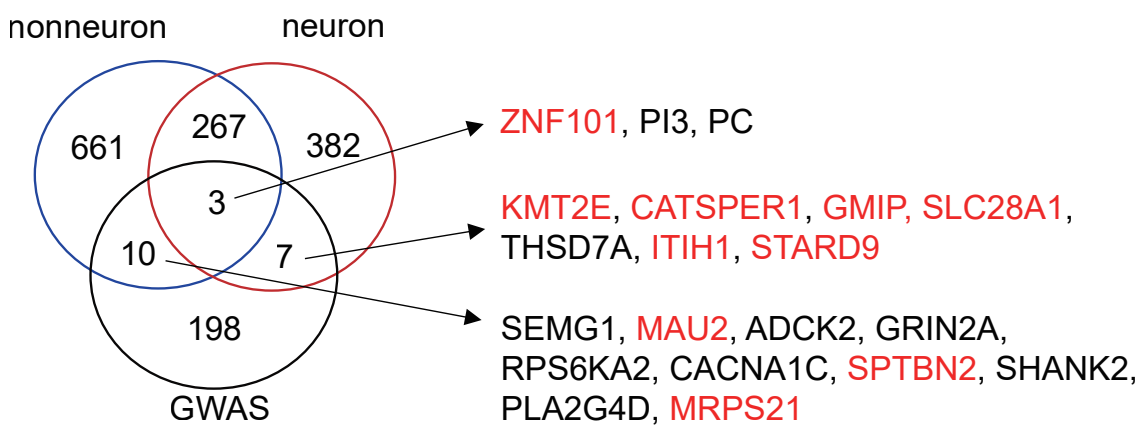


medRxiv preprint doi: https://doi.org/10.1101/2020.12.10.20246405; this version posted December 11, 2020. The copyright holder for this preprint (which was not certified by peer review) is the author/funder, who has granted medRxiv a license to display the preprint in perpetuity.

It is made available under a CC-BY-NC-ND 4.0 International license .

a

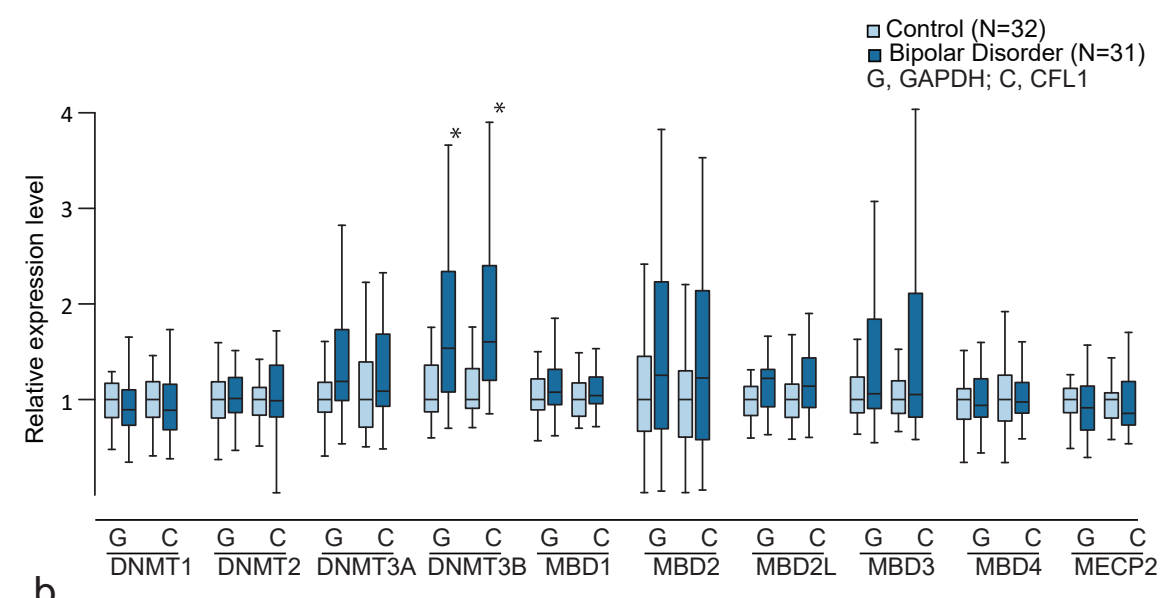

$\mathrm{b}$
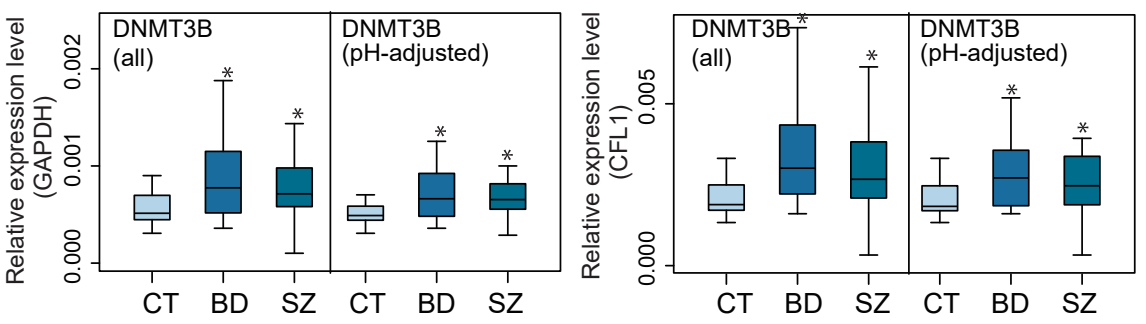